\title{
STUDY OF CLINICAL AND HISTOPATHOLOGICAL PRESENTATION OF OVARIAN MASSES IN TEACHING HOSPITAL
}

\author{
G. Shobha1 ${ }^{1}$ P. Supriya ${ }^{2}$, Nissy Jacintha $B^{3}$
}

1 Professor, Department of Obstetrics and Gynaecology, Gandhi Medical College.

${ }^{2}$ Assistant Professor, Department of Obstetrics and Gynaecology, Gandhi Medical College.

${ }^{3}$ Senior Resident, Gandhi Medical College.

\section{ABSTRACT}

\section{OBJECTIVE}

To study the clinical and histopathological presentation of ovarian masses.

\section{METHOD}

Hospital based retrospective study done on 200 patients in the Department of Gynaecology, Gandhi Hospital, Secunderabad, who are clinically and sonologically diagnosed to have ovarian masses during the period of January 2014 to September 2015.

\section{RESULTS}

The prevalence of ovarian masses in our study was $0.6 \%$. Among the 200 cases, $60.5 \%$ were neoplastic and $39.5 \%$ were nonneoplastic. Among neoplasms 90\% were benign, $8.26 \%$ malignant and 1.65\% borderline. Serous cystadenoma was the commonest benign tumor (55\%) followed by Mucinous (27.5\%) and Dermoid (15.5\%). Most common malignant ovarian tumor was Serous cystadenocarcinoma (60\%).

\section{CONCLUSION}

Ovarian neoplasms have twice the incidence of non-neoplasms. Maximum incidence of malignancy is in between 40-49 years of age group. Non-specific abdominal symptoms should be given more importance, as it may be the only clue to the underlying malignancy. So effective clinical, biochemical and radiological diagnosis helps in early intervention to increase the survival rates in malignancy. Sixty million people are affected with glaucoma worldwide and more than 20 million have PACG. Of these more than 5 million with PACG are blind, which is twice more than POAG. Early detection and timely treatment with Nd:YAG laser iridotomy and associated complications determine visual outcome.

\section{KEYWORDS}

Ovarian Masses, Clinical, Histopathological Presentation.

HOW TO CITE THIS ARTICLE: Shobha G, Supriya P, Nissy Jacintha B. Study of clinical and histopathological presentation of ovarian masses in teaching hospital. J. Evolution Med. Dent. Sci. 2016;5(11):459-461, DOI: 10.14260/jemds/2016/105

\section{INTRODUCTION \\ Among women worldwide, ovarian cancer is the sixth most common cancer. The age standardized incidence rate worldwide is $6.6 / 100,000$. Ovarian cancer is the seventh leading cause of cancer deaths. The age standardized mortality rate is $4.0 / 100,000 .{ }^{1}$ In most of the population-based cancer registries in India, ovarian cancer is the third leading site of cancer among women after cervix and breast cancer. The age- adjusted incidence rates of ovarian cancer vary between 5.4 and 8.0 per 100,000 population in different parts of the country. ${ }^{2}$ The Age Specific Incidence Rate (ASIR) for ovarian cancer revealed that the disease increases from 35 years of age and reaches a peak between the ages 55-64. The trend analysis by period showed an increasing trend in the incidence rate of ovarian cancer in most of the registries with a mean annual percentage increase in ASR ranged from $0.7 \%$ to $2.4 \% .^{3}$}

Financial or Other, Competing Interest: None.

Submission 22-12-2015, Peer Review 19-01-2016,

Acceptance 25-01-2016, Published 05-02-2016.

Corresponding Author:

Dr. G. Shobha,

LIG 1/4 GVN Medical Centre, BK Guda,

SR Nagar, Hyderabad-500038.

E-mail:dr.shobhagumdal@gmail.com,supriyabula@gmail.com DOI: $10.14260 /$ jemds/2016/105
The 5-year relative survival rate is around $25.4 \%$ for ovarian malignancy. ${ }^{4}$ Higher survival is noted in patients younger than 35 years and with localized early-stage disease. Clinical, biochemical and radiological assistance was used for earlier detection and accurate diagnosis, thereby to reduce the burden of morbidity and mortality. So this study has been done to note the clinical presentation and histopathological pattern of ovarian masses in our hospital over 2 years.

\section{METHODOLOGY}

This is a hospital based retrospective study done on 200 patients in the Department of Gynaecology OPD, Gandhi Hospital, Secunderabad who are clinically and sonologically diagnosed to have ovarian neoplasms during the period of January 2014 to September 2015. Patients with ovarian masses, who were surgically managed, were included in the study. Patients with non-ovarian masses and those with ovarian masses who were conservatively managed were excluded. Clinical details such as patient's age, age of menarche, post-menopausal status, obstetric history, presenting symptoms and surgery details were noted. Histopathological examinations of the excised specimens were conducted by the Pathology Department of our hospital by appropriate stains (Hematoxylin and Eosin). Based on histopathological observations, the ovarian masses were 
classified as benign and malignant and their incidence were studied.

\section{RESULTS}

Out of the total gynaecology OPD, prevalence of ovarian masses which had surgical intervention was $0.6 \%(\mathrm{n}=200)$ and that of ovarian neoplasms was $0.4 \%$. Among the ovarian masses, neoplasms accounted for $60.5 \%(121 / 200)$ and nonneoplastic lesions 39.5\% (79/205). Out of the neoplastic lesions, 90\% (109/121) were benign, $8.26 \%$ malignant $(10 / 121)$ and 1.65\% (2/121) borderline lesion.

Maximum number of benign cases $(40 / 107)$ was noted in the 30-39 years age group and the malignant cases were more common (6/12) in the 40-49 years age group. The distribution of ovarian masses in different age groups is shown in Table 1 and Chart 1.

\begin{tabular}{|c|c|c|c|c|}
\hline $\begin{array}{c}\text { Age } \\
\text { Distribution }\end{array}$ & $\begin{array}{c}\text { Non } \\
\text { neoplastic }\end{array}$ & Benign & Malignant & Borderline \\
\hline $10-19$ yrs & 4 & 5 & - & - \\
\hline $20-29$ yrs & 19 & 22 & 1 & - \\
\hline $30-39$ yrs & 28 & 40 & 1 & - \\
\hline $40-49$ yrs & 24 & 34 & 6 & 1 \\
\hline $50-59$ yrs & 3 & 7 & 2 & 1 \\
\hline 60 yrs & 1 & 1 & - & - \\
\hline \multicolumn{5}{|c|}{ Table 1: Age Distribution } \\
\hline
\end{tabular}

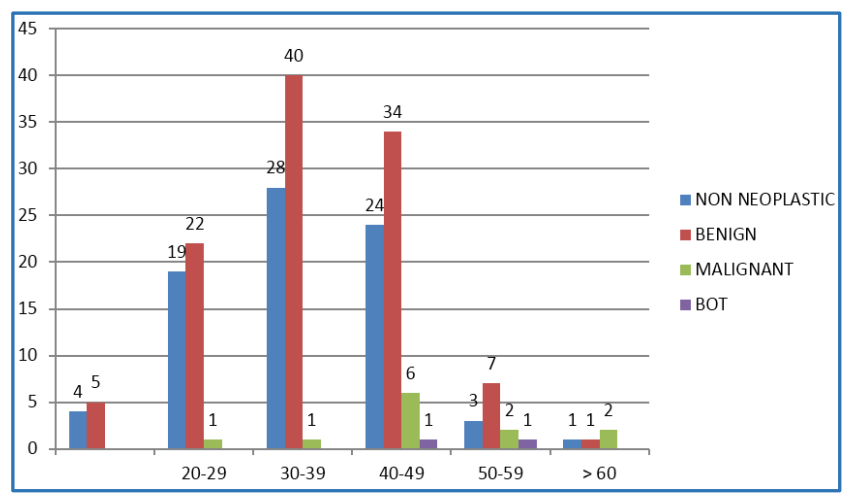

Chart 1: Demographic details, parity and history of sterilization of the study group are shown in Table 2

\begin{tabular}{|c|c|c|c|c|}
\hline Parameters & $\begin{array}{c}\text { Non } \\
\text { neoplastic }\end{array}$ & Benign & Malignant & BOT \\
\hline $\begin{array}{c}\text { Age of } \\
\text { menarche } \\
11-12 \\
13-14 \\
15-16\end{array}$ & $\begin{array}{c}40 \\
30 \\
9\end{array}$ & $\begin{array}{l}40 \\
54 \\
15\end{array}$ & $\begin{array}{l}6 \\
3 \\
1\end{array}$ & $\begin{array}{c}1 \\
1 \\
\text { Nil }\end{array}$ \\
\hline $\begin{array}{c}\text { Age group } \\
\text { Reproductive } \\
\text { Post } \\
\text { menopausal } \\
\end{array}$ & $\begin{array}{c}74 \\
5\end{array}$ & $\begin{array}{l}97 \\
12\end{array}$ & $\begin{array}{l}7 \\
3\end{array}$ & $\begin{array}{l}1 \\
1\end{array}$ \\
\hline $\begin{array}{c}\text { Sterilization } \\
\text { Yes } \\
\text { No } \\
\end{array}$ & $\begin{array}{c}72 \\
7 \\
\end{array}$ & $\begin{array}{c}100 \\
9\end{array}$ & $\begin{array}{l}10 \\
\mathrm{Nil}\end{array}$ & $\begin{array}{c}2 \\
\text { Nil } \\
\end{array}$ \\
\hline $\begin{array}{c}\text { Parity } \\
\text { Nulligravida } \\
1,2 \\
>3\end{array}$ & $\begin{array}{c}2 \\
74 \\
2\end{array}$ & $\begin{array}{l}44 \\
32 \\
33\end{array}$ & $\begin{array}{c}\text { Nil } \\
8 \\
2\end{array}$ & $\begin{array}{c}\text { Nil } \\
1 \\
1\end{array}$ \\
\hline \multicolumn{5}{|c|}{$\begin{array}{c}\text { Table 2: Demographic and Obstetric } \\
\text { profile among ovarian masses }\end{array}$} \\
\hline
\end{tabular}

Among the non-neoplastic masses, the commonest was endometriotic cyst (29\%). Histopathological pattern of nonneoplastic ovarian masses is shown in Chart 2.

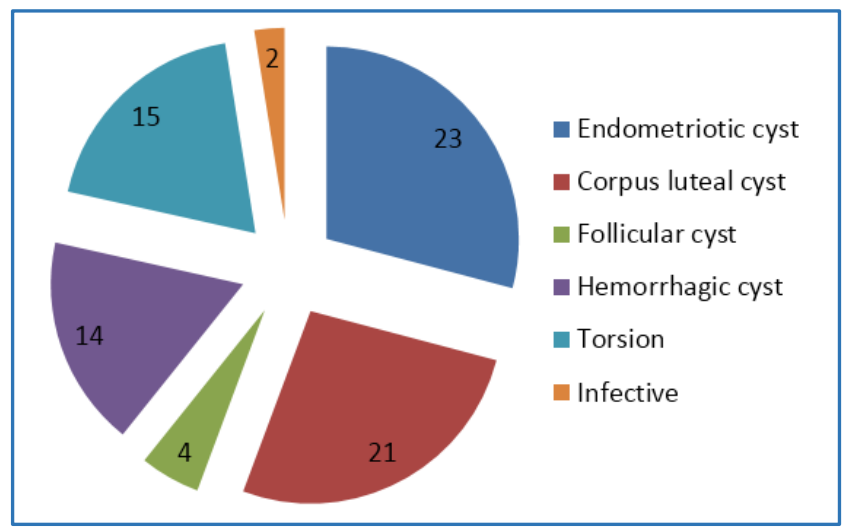

Chart 2: Histopathological pattern of non-neoplastic ovarian masses

\begin{tabular}{|c|c|c|c|}
\hline Symptoms & $\begin{array}{c}\text { Non } \\
\text { neoplastic }\end{array}$ & Benign & Malignant \\
\hline Pain abdomen & $70 \%$ & $66 \%$ & $40 \%$ \\
Mass abdomen & $\mathrm{Nil}$ & $8 \%$ & $2 \%$ \\
$\begin{array}{c}\text { Abdominal } \\
\text { symp }\end{array}$ & $\mathrm{Nil}$ & $2 \%$ & $30 \%$ \\
Menstrual symp & $30 \%$ & $20 \%$ & $4 \%$ \\
Urinary symp & $\mathrm{Nil}$ & $4 \%$ & $\mathrm{Nil}$ \\
Constitutional & $\mathrm{Nil}$ & $\mathrm{Nil}$ & $20 \%$ \\
Asymptomatic & Nil & Nil & $4 \%$ \\
\hline Table 3: Clinical Presentation of Ovarian Masses \\
\hline
\end{tabular}

Abdominal pain followed by abnormal menstrual pattern was the predominant presenting symptom in patients with both non-neoplastic and benign ovarian masses. On the contrary, malignant group predominantly presented with vague abdominal and constitutional symptoms.

Serous cystadenoma (55\%) followed by Mucinous cystadenoma (27.5\%) and Benign cystic teratoma (15.5\%) were the commonest benign ovarian tumors. Of the two Borderline Ovarian Tumors (BOT), two were Serous subtype. Of the 12 malignant ovarian tumors, 8 were Surface epithelial tumors, 2 were non-epithelial tumors. Among the surface epithelial tumors, Serous cystadenocarcinoma was the most common (60\%) followed by Mucinous cystadenocarcinoma (20\%).

\section{DISCUSSION}

In the present study, out of total Gynaecology OPD incidence of ovarian masses which had surgical intervention is $0.6 \%$ and that of ovarian neoplasms is $0.4 \%$. Ovarian neoplasms have almost twice the incidence of non-neoplastic lesions. Maximum numbers of ovarian malignancies were found in the 40-49 years age group, which is comparable with Soumini Gangaraju, et al. ${ }^{5}$ study. Results from European studies show that the Age-specific incidence rates rise sharply from around 40-44 years, peaking among women in their 70s and 80s. The number of cases is highest among women in their 60 s and $70 \mathrm{~s}$, 
accounting for almost half the diagnoses. ${ }^{6}$ Thus, the increasing trend of ovarian neoplasms in younger age group in our population is noted.

Nulliparity is not a significant risk factor for ovarian neoplasms in our study because of small number. Among the ovarian neoplasms, $90 \%$ were benign and $8.26 \%$ were malignant. These findings are comparable with Jha, et al. ${ }^{7}$ study. Pain in abdomen is the commonest presenting symptom both in non-neoplastic and benign ovarian masses, whereas vague abdominal symptoms and constitutional symptoms were predominant in the malignant group. Asymptomatic presentation is more common in malignancy compared to the benign neoplasms.

Out of benign tumors, Serous cystadenoma accounted for $55 \%$, Mucinous cystadenoma $27.5 \%$ and Mature cystic teratoma $15.5 \%$. This is comparable with Manivasakan et al. 8 study.

Of the malignant tumors, Serous cystadenocarcinoma accounted for $60 \%$ followed by $20 \%$ Mucinous cystadenocarcinoma, which is similar to the Jha et al. ${ }^{7}$ study. Asymptomatic nature and vague constitutional complaints of the malignant ovarian tumors are responsible for their late presentation and thereby its mortality and morbidity.

\section{CONCLUSION}

Ovarian neoplasms incidence is twice that of non-neoplastic lesions. Maximum incidence of malignancy is in between 4049 years of age group. Non-specific abdominal symptoms should be given more importance, as it may be the only clue to the underlying malignancy. So effective clinical, biochemical and radiological diagnosis helps in early intervention to increase the survival rates in malignancy.

\section{REFERENCES}

1. Parkin DM, Bray F, Ferlay J, et al. Global cancer statistics, 2002. CA Cancer J Clin. 2005;55(2):74-108.

2. Consolidated Report of Population Based Cancer Registries 2001-2004. National Cancer Registry Program. Indian Council of Medical Research. Bangalore: 2006.

3. Murthy NS, Shalini S, Suman G, et al. Changing trends in incidence of ovarian cancer-the Indian scenario. Asian Pac J Cancer Prev. 2009;10(6):1025-30.

4. Yeole BB, Kumar AV, Kurkure A, et al. Population-based survival from cancers of breast, cervix and ovary in women in Mumbai, India. Asian Pac J Cancer Prev. 2004;5(3):308-15.

5. Soumini Gangaraju, Lavanya Kumari Sarella, Lakshmi Chaveli V, et al. Scenario of ovarian mass lesions at a teaching hospital in Andhra Pradesh, India. Int J Reprod Contracept Obstet Gynecol. 2015;4(4):982-989.

6. Poole J, Nordin A. Trent cancer registry. Profile of ovarian cancer in England, 2012.

7. Jha R, Karki S. Histological pattern of ovarian tumors and their age distribution. Nepal Med Coll J 2008;10:81-5.

8. Manivasakan J, et al. A study of benign adnexal masses. Int J Reprod Contracept Obstet Gynaecol. 2012;1(1):12-6. 